\begin{tabular}{|c|c|c|c|}
\hline \multirow{3}{*}{$\frac{x}{12}=3$} & & $\mathbf{I}$ & \multirow{4}{*}{$\begin{array}{l}\text { Teterwatlomat } \\
\text { Journai } \\
\text { of } \\
\text { Herbat } \\
\text { Medictene }\end{array}$} \\
\hline & International Journal of Herbal Medicine & J & \\
\hline & \multirow[t]{2}{*}{ Available online at www.florajournal.com } & $\mathbf{H}$ & \\
\hline & & $\mathbf{M}$ & \\
\hline
\end{tabular}

E-ISSN: 2321-2187

P-ISSN: 2394-0514

www.florajournal.com

IJHM 2020; 8(6): 36-49

Received: 20-09-2020

Accepted: 27-10-2020

\section{Mohd Aleem}

Department of Pharmacology,

National Institute of Unani

Medicine, Kottigepalya Magadi

Main Road, Bangalore,

Karnataka, India

\section{Md Imran Khan}

Department of Pharmacology,

National Institute of Unani

Medicine, Kottigepalya Magadi

Main Road, Bangalore,

Karnataka, India

\section{Fayyaz Ahmad Shakshaz}

Department of Pharmacology,

National Institute of Unani

Medicine, Kottigepalya Magadi

Main Road, Bangalore,

Karnataka, India

Nusra Akbari

Department of Pharmacology, National Institute of Unani

Medicine, Kottigepalya Magadi

Main Road, Bangalore,

Karnataka, India

Daraksha Anwar

Department of Pharmacology,

National Institute of Unani

Medicine, Kottigepalya Magadi

Main Road, Bangalore,

Karnataka, India
Corresponding Author:

\section{Mohd Aleem}

Department of Pharmacology,

National Institute of Unani

Medicine, Kottigepalya Magadi

Main Road, Bangalore,

Karnataka, India

\section{Botany, phytochemistry and antimicrobial activity of ginger (Zingiber officinale): A review}

\author{
Mohd Aleem, Md Imran Khan, Fayyaz Ahmad Shakshaz, Nusra Akbari \\ and Daraksha Anwar
}

DOI: https://doi.org/10.22271/flora.2020.v8.i6a.705

\begin{abstract}
Antibiotic resistance in every corner of the planet is growing to dangerously high levels. New mechanisms of resistance are emerging and spreading globally which threatens our ability to treat common infectious diseases. Many scientists documented some plants having antimicrobial properties. Zingiber officinale Roscoe ( $Z O)$, the most recognised member of Zingiber, is one of them. This review aims to validate the antimicrobial activity of ginger. The information and data on $\mathrm{ZO}$ were collated from various resources like ethnobotanical textbooks, Pub Med, Google Scholar, Science Direct, Web of Science, and Scopus. $Z O$ has many medicinal, nutritional and ethnomedical values and is commonly used as a spice, flavouring agent and herbal remedy worldwide. In addition to giving ginger its pungent aroma, volatile oil gingerol and other pungent principles are the most medically potent since they inhibit the production of prostaglandin and leukotriene, which are chemicals that affect blood flow and inflammation. Traditionally, it has been used as an herbal remedy for centuries in Ayurvedic, TibbUnani, Chinese, Islamic, Africans, the Caribbean and many other medicinal systems to cure a variety of diseases like throat infections, asthma, inflammation, dyspepsia, loss of appetite, palpitation, constipation and indigestion, colds, arthritis, nausea, hypertension, migraines, and many more. It has a high proportion of $\alpha$-Zingiberene, $\beta$-sesquiphellandrene, (E,E)- $\alpha$-farnesene, geranial and ar-curcumene. The ZO extracts, essential oil and chemical constituents exhibited antimicrobial, anticonvulsant, analgesic, antiinflammatory, antiulcer, immunomodulatory, and other beneficial activities. The research suggests that there are marked antimicrobial activities in the ginger that could be beneficial and applied in various research areas, such as the pharmaceutical and food industries. To understand the molecular mechanisms by which these effects are exerted, more research may be required.
\end{abstract}

Keywords: Ginger, Zingiber officinale, antimicrobial, terpenes, zingiberene

\section{Introduction}

In 1911, Salvarsan and its derivative neoarsphenamine were used against syphilis as the first antimicrobial drugs successfully used against life-threatening infectious diseases. This breakthrough, which transformed the definition of drug therapy, was named the "magic bullet," and the word "chemotherapy" was introduced ${ }^{[1]}$. After the Golden Age revolution, when virtually all necessary antibiotics were discovered, and the main chemotherapy problems were solved in the 1960s, history is now repeating itself. These exciting compounds are at risk of losing their potency due to increased microbial resistance ${ }^{[2]}$. Antibiotic resistance in every corner of the planet is growing to dangerously high levels. New mechanisms of resistance are emerging and spreading globally, threatening our ability to treat common infectious diseases. As antibiotics become less successful, a rising list of infections such as pneumonia, tuberculosis, blood poisoning, gonorrhoea, and foodborne diseases are becoming more complicated and even impossible to treat ${ }^{[3,4]}$. Consequently, there is an urgent need to find an alternative to chemotherapy drugs, especially those of plant origin, which are readily available and have substantially fewer side effects in treating diseases. The use of higher plants and their extracts in many parts of the world has long been practiced to treat infectious diseases ${ }^{[5,6]}$.

Since the late 19th century, scientific studies have reported the antimicrobial existence of individual spices, herbs, and their components. Approximately 80 per cent of the world's population currently depends on botanical preparations as medicines to meet their health needs. Fortunately, it is not clear that even long-term use of these substances would cause any side effects. Since ancient times they have been widely used in many countries of Asia and Africa. However, in recent years, the use of spices/herbs in developing countries has also steadily increased because of their beneficial effects ${ }^{[7,8]}$.

Many scientists documented some plants having antimicrobial properties. Zingiber officinale is one of them ${ }^{[9]}$. It has many medicinal, nutritional, and ethnomedical values and is commonly used as a spice, flavouring agent, and herbal remedy worldwide ${ }^{[10]}$. 
In addition to giving ginger its pungent aroma, volatile oil (gingerol) and other pungent principles are the most medically potent ${ }^{[9]}$. The characteristic odour and taste of ginger are caused by a mixture of non-volatile pungent compounds such as zingerone, shogaols, and gingerols ${ }^{[11]}$. Ginger rhizome is one of the world's best-known spices and has been used for its health benefits in complementary medicine dates back 2,500 years ${ }^{[12]}$. It is cultivated in China, Nepal, India, Bangladesh, United States, Taiwan, Jamaica, Nigeria, and Indonesia. The principal producers and exporters are India and China. It has been used in Ayurvedic, Tibb-Unani, Chinese, Islamic, Africans, the Caribbean, and many other medicinal systems to cure a variety of diseases like throat infections, asthma, inflammation, palpitation, constipation, indigestion, arthritis, hypertension, migraines, and many more $[10,13,14]$. Ginger is a food spice that also has been accepted by the American Diabetic Association as a nutraceutical. Nutraceutics are functional foods that provide essential health benefits, including disease prevention and treatment ${ }^{[15]}$.

In recent decades, $Z O$ has been extensively investigated by advanced scientific techniques for medicinal properties, and many bioactive compounds have been isolated from various parts of the plant ${ }^{[16]}$. It has a high proportion of $\alpha-$ Zingiberene, $\beta$-sesquiphellandrene, $(\mathrm{E}, \mathrm{E})-\quad \alpha$-farnesene, geranial, and ar-curcumene ${ }^{[15]}$. Its extracts and active compound exhibited antimicrobial, anticonvulsant, analgesic, anti-inflammatory, antiulcer, gastric antisecretory, antidiabetic, nephroprotective, hepatoprotective, antitumor, anticancer, antispasmodic, antithrombotic, hypocholesterolemic, antiallergic, antiserotonergic, anticholinergic, antioxidant, larvicidal, immunomodulatory activities and other beneficial activities ${ }^{[16,17]}$. Also, gingerol and its derivatives are recognised as promising potential cancer-preventive and anticancer agents ${ }^{[18]}$.

\section{Material and methods}

A systematic ginger-related literature quest was carried out to collect all relevant information on common uses, phytochemicals, and pharmacological activities. Publicly available databases and primary sources, including PubMed, SciFinder, Web of Science, Science Direct, PhD dissertations, have been scanned. A large number of literature articles published from 2001 to 2019 were reviewed. Searching for regarding the information on the ginger was carried out by using Latin names, Zingiber officinale Roscoe, and vernacular names as Zanjabil, Ginger, and Sonth. The extracted data included isolated compounds and antimicrobial activity. The name of species has been validated using 'The Plant List' (www.theplantlist.org). All chemical structures images were taken from PubChem.

\section{Vernacular names}

Arabic: Zanjabil; China: Gan-Jiang (dried), Shēng jiāng (fresh); Dutch: Gember; English: Ginger; French: Gingembre; German: Ingwer; Greek: Piperoriza; Japan: Shouga; Nepal: Agnimanth, Sutho; Persian: Amveel, Zanjabil; Russian: Imbir; Spanish: Jengibre; Sanskrit: Adraka (Fresh), Shunthi (Dried), Shringaveran; Urdu and Hindi: Adrak (fresh), Sonth (dry) ${ }^{[19-21]}$.

\section{Botany}

The genus Zingiber, belonging to the family Zingiberaceae, comprises about 85 species of herbs, mostly grown in Asia, South, Central America, and Africa ${ }^{[13]}$. Zingiber officinale Roscoe is the accepted name of a species in the genus
Zingiber. It is a tropical plant that grows well in hot and humid climates. There are three known ginger types: giant ginger or white ginger (Zingiber officinale var. Roscoe), small white ginger, (Zingiber officinale var. Amarum), and red ginger (Zingiber officinale var. Rubrum). Zingiber officinale Roscoe is one of the most commonly used herbs in Asia, has been empirically used to treat various disorders ${ }^{[16]}$.

It is a perennial, herbaceous plant that grows up to a height of about $100 \mathrm{~cm}$. The leaves develop from the branched rhizome [11]. Leaves are simple, alternate, distichous narrow oblonglanceolate, 2-3 cm broad with sheathing bases, the blade gradually tapering to point. The inflorescence is solitary, lateral radical pedunculate oblong cylindrical spikes. Flowers are rare, which resemble the orchids, consisting of several overlapping scales on an elongated stalk. Each flower has three yellowish-orange petals with an additional purplish, liplike structure. Rhizomes are aromatic, thick lobed, pale yellowish. The herb develops several lateral shoots in clumps, which begin to dry when the plant matures ${ }^{[11,13]}$.

\section{Chemical constituent}

The chemical compounds found in ginger rhizome was identified by gas chromatography-mass spectrometry, gas chromatography with flame ionisation detection, highperformance liquid chromatography, and liquid chromatography-mass spectrometry. Gas chromatography helps detect volatile compounds with low molecular weight, whereas liquid chromatography has distinguished polar compounds ${ }^{[22]}$. The powdered ginger sample's nutritional composition consists of carbohydrates, protein, fat, dietary fibre, iron, calcium, vitamin $\mathrm{C}$, and carotene ${ }^{[23]}$. The main components of ginger rhizome are essential oils, terpenes (zingiberene, beta-bisabolene, alpha-farnesene, betasesquiphellandrene, alpha-curcumene) Table 1, phenol compounds (gingerol, shogaol, paradols etc.) Table 2 and flavonoid compounds (Luteolin, rutin etc.) Table 3 [16, 23]. Flavonoids and phenolic compounds are the most common secondary metabolites in plants and are found in food and nutraceutical products ${ }^{[16]}$.

Ginger contains essential oils and oleoresins, which create a robust, sour, and pungent flavour ${ }^{[22]}$. The most important compounds responsible for ginger's medicinal activities are classified into non-volatile and volatile compounds ${ }^{[11,16]}$. The three main groups of compounds present in volatile oils were monoterpenoids, sesquiterpenoids, and aldehydes responsible for ginger's sensory characteristics ${ }^{[22,24]}$. The sesquiterpene derivatives (-)- zingiberene, (+)-curcumene, (-)- $\beta$ sesquiphelandrene, and $\beta$-bisabolene are responsible for the aroma ${ }^{[16]}$. Camphene has a terpeney camphoraceous taste, while sabinene has a hot, oily-peppery, and a slightly pungent spicy taste. $\alpha$-Curcumene has a distinctive turmeric odour and a mildly pungent bitter taste. Zingiberene has a warm, woodyspicy, and very persistent odour, while $\alpha$-farnesene has a very mild, sweet, and warm odour. Neral and geranial are commonly used as a strong lemon fragrance chemical [24]. Non-volatile phenylpropanoid-derived compounds, particularly gingerols, shogaols, paradols, and zingerone, are responsible for the pungent taste ${ }^{[11,16,22]}$. Oleoresins derived from various solvents include eugenol, zingerone, trans-6shogaol, and geranial as the main compounds ${ }^{[22]}$. The elements responsible for the spicy taste of ginger have been known as gingerols ${ }^{[16]}$. Zingerone developed from gingerols during drying or cooking is responsible for the warm pungent sensation in the mouth and many of the pharmacological effects of the plant are also recorded ${ }^{[11]}$. 
Table 1: Classification and structure of chemical constituent of $Z O$

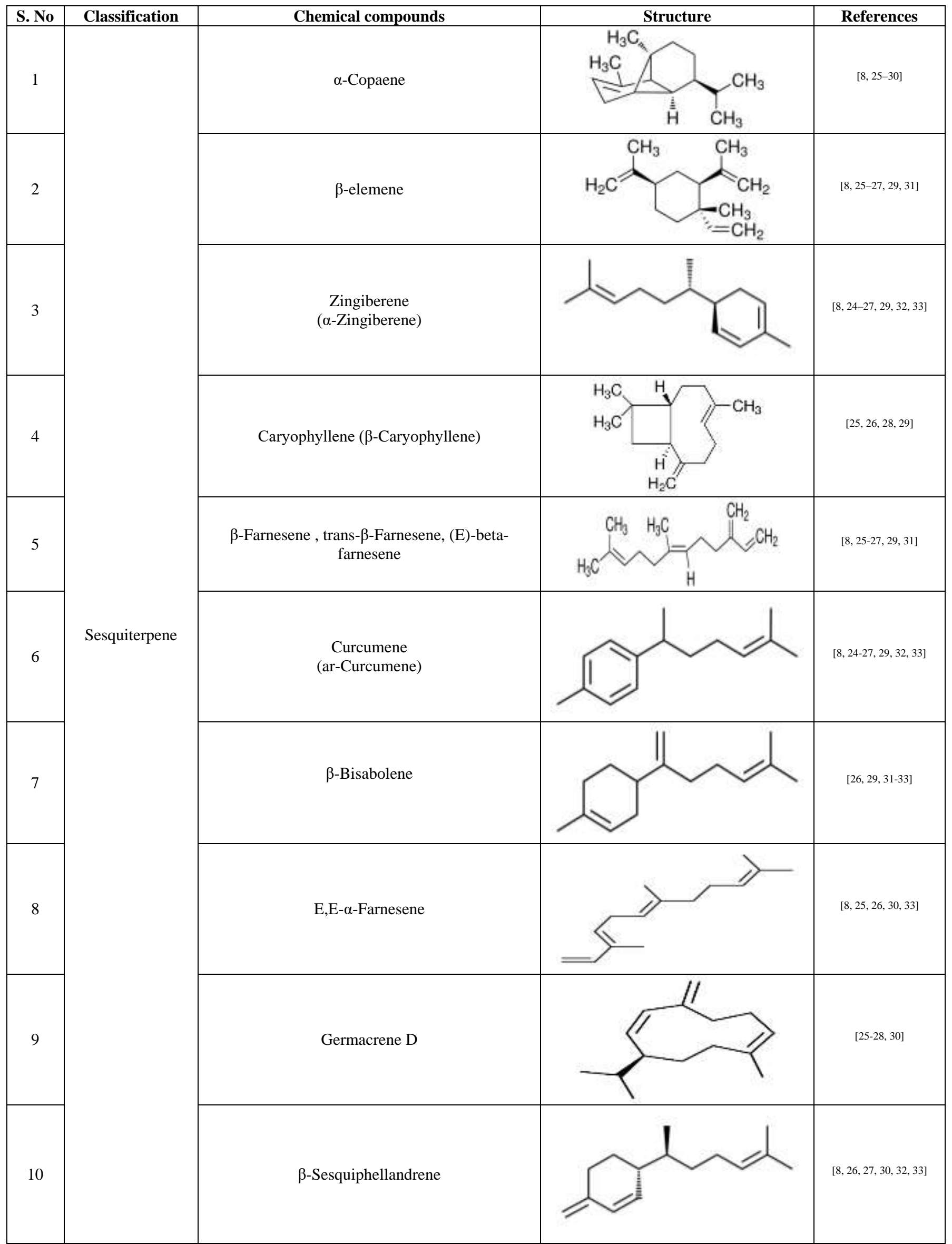




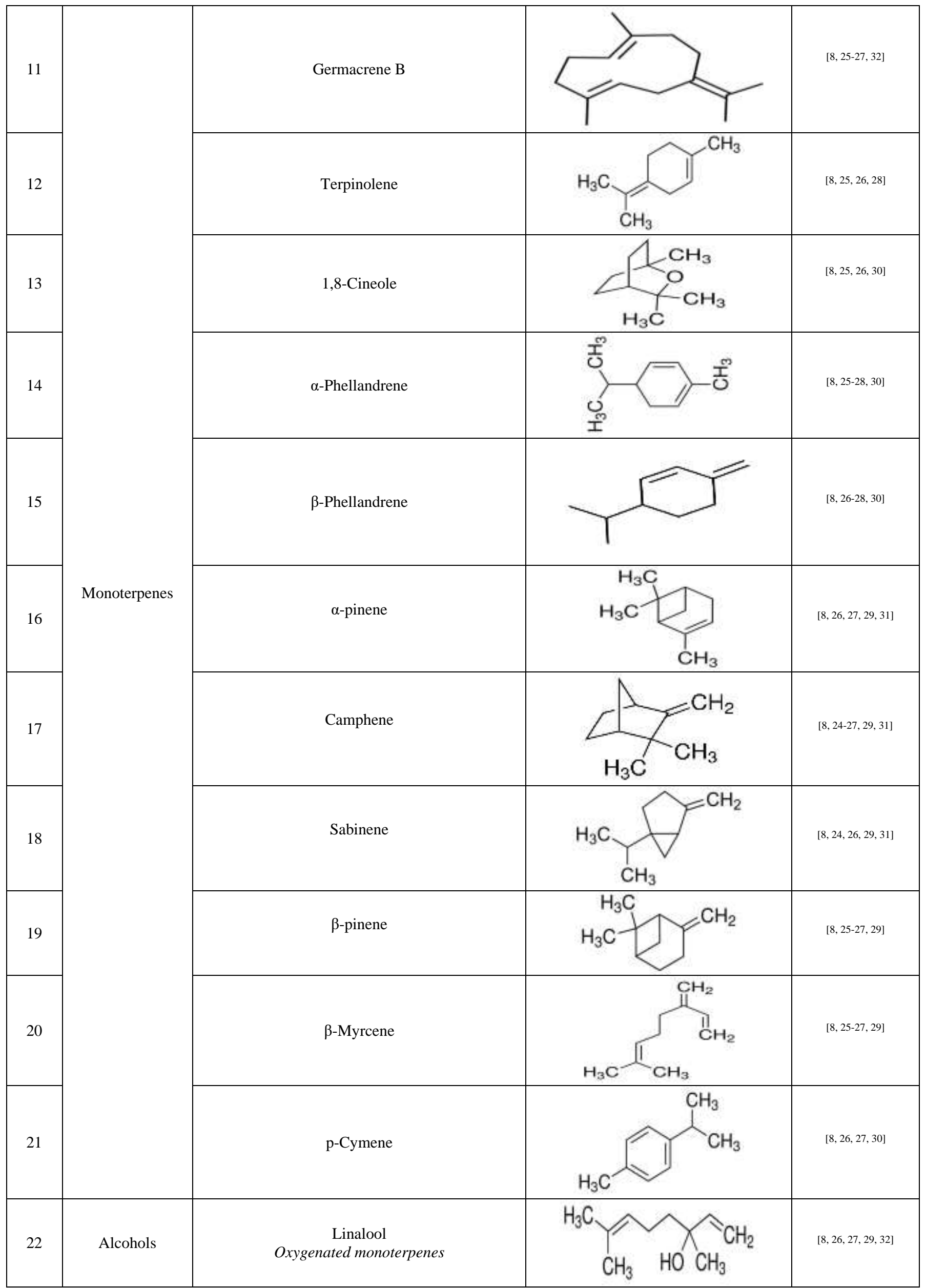




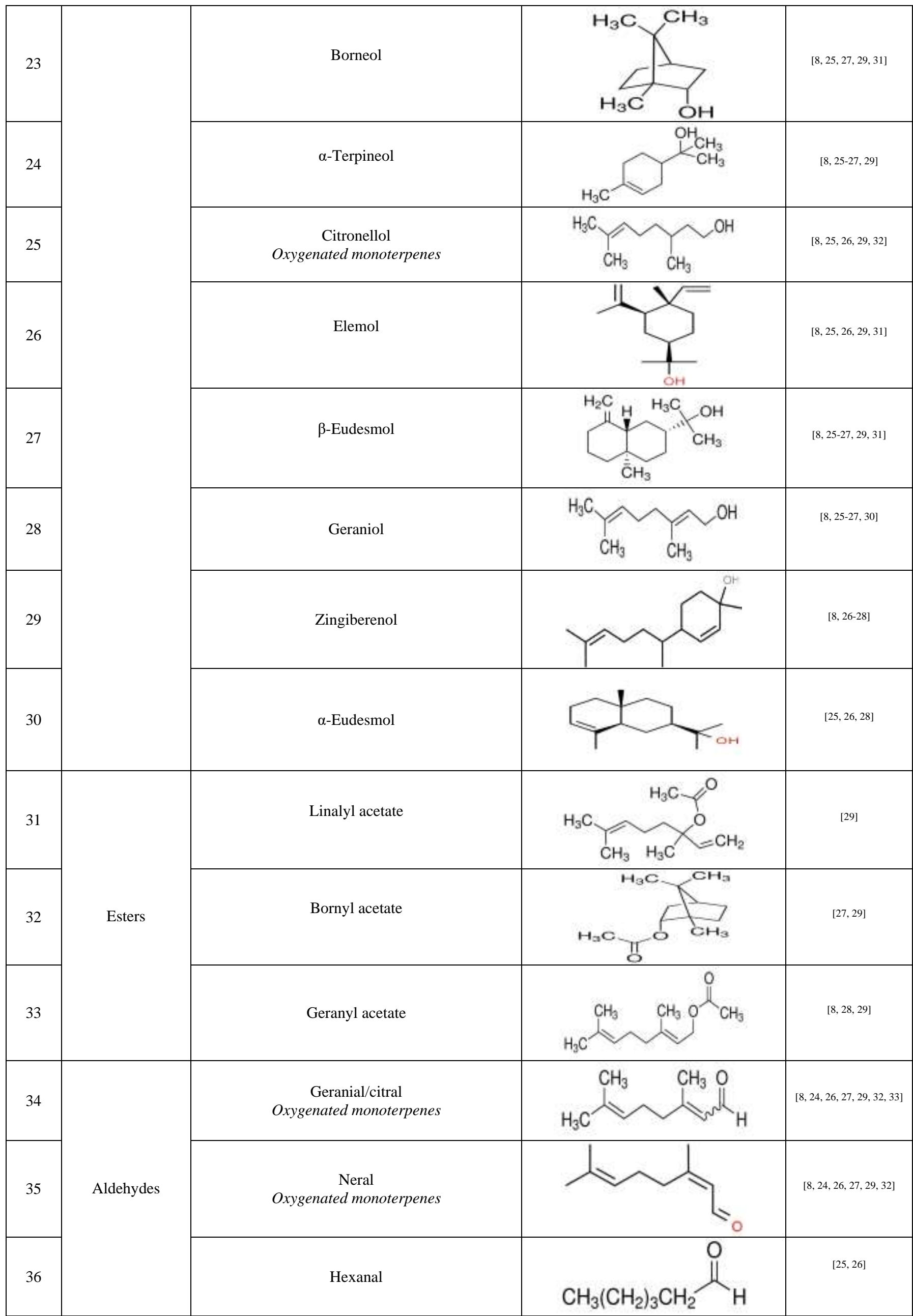




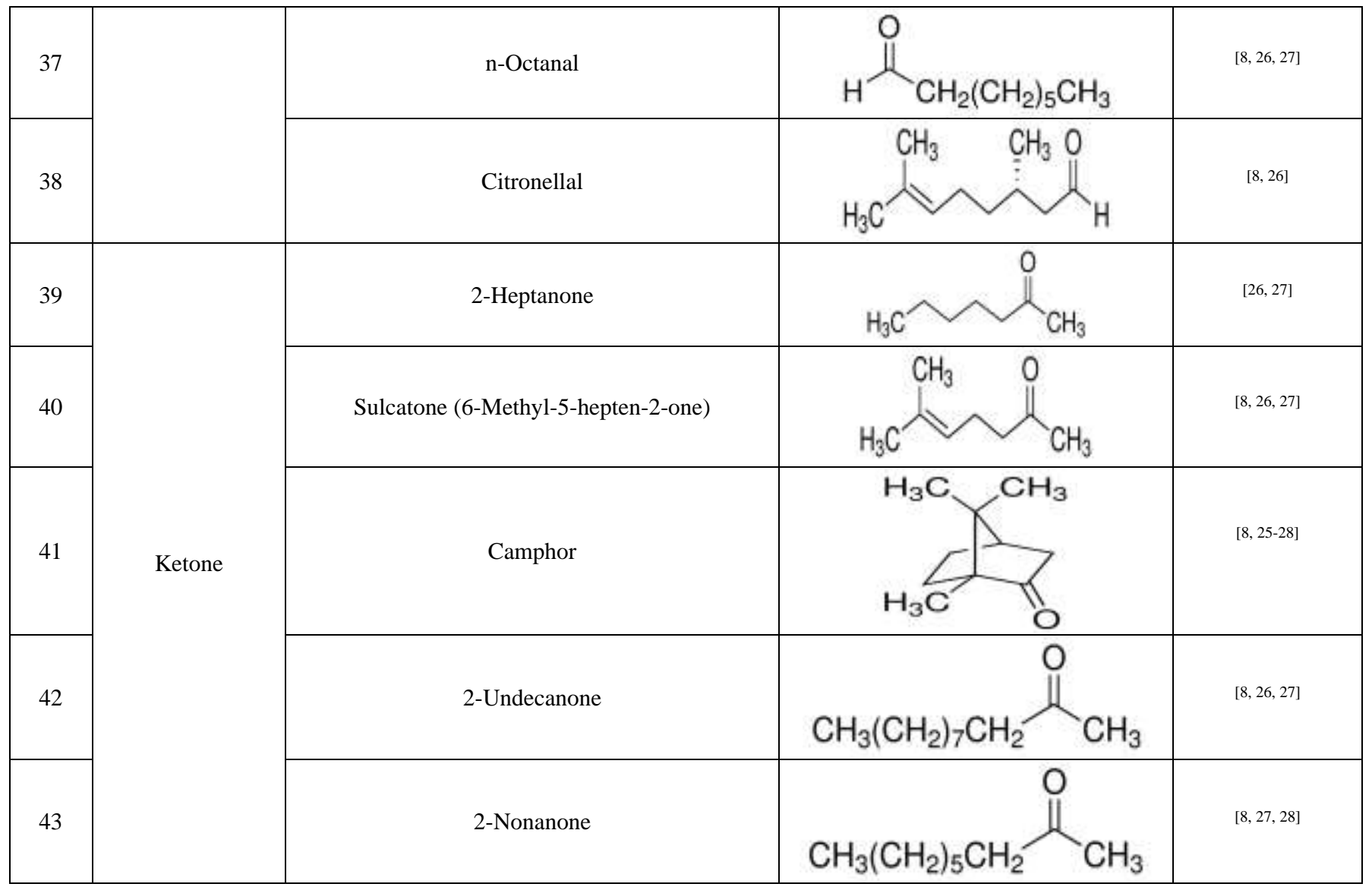

Table 2: Phenolic compounds of ginger

\begin{tabular}{|c|c|c|c|}
\hline S. No & Name & Structure & References \\
\hline 1 & $\begin{array}{c}\text { Gingerol } \\
\text { ([4]-, [6]-, [7]-, [8]-, [10]- gingerol, Methyl [4]-, Methyl [6]-gingerol) }\end{array}$ & & [34-37] \\
\hline 2 & $\begin{array}{c}\text { Shogaol } \\
\text { ([4]-, [6]-, [8]-, [10]-, [12]-Shogaol, Methyl [6]-, Methyl 8]-shogaol) }\end{array}$ & & [34-37] \\
\hline 3 & $\begin{array}{c}\text { Paradol } \\
\text { ([6]-, [7]-, [8]-, [9]-, [10]-, [11]-, [13]- paradol, Methyl [6]-paradol) }\end{array}$ & & [36] \\
\hline 4 & Gallic acid & & {$[29,37-41]$} \\
\hline 5 & Protocatechuic acid & & {$[29,37,38]$} \\
\hline
\end{tabular}




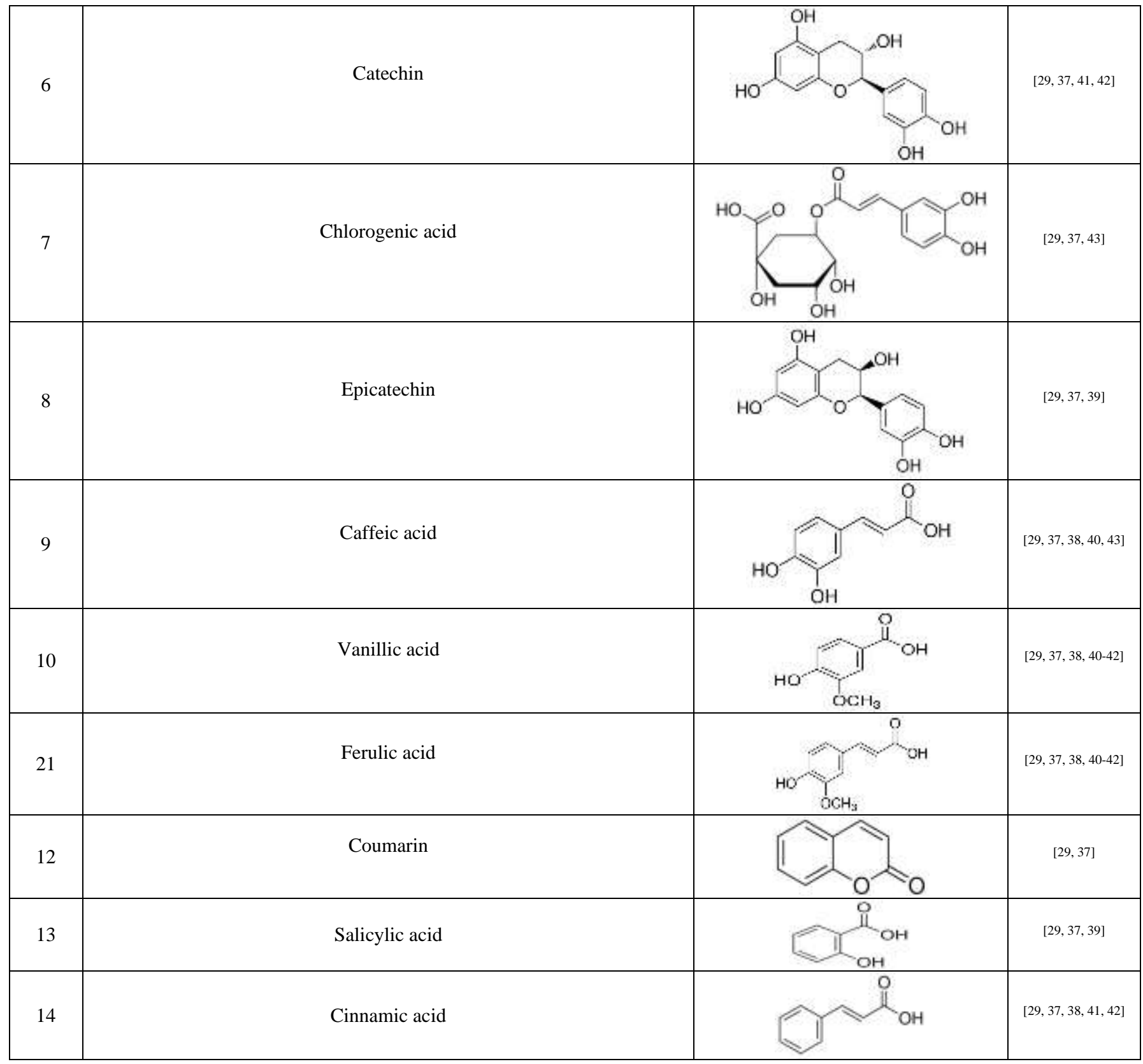

Table 3: Flavonoid compounds of ginger

\begin{tabular}{|c|c|c|c|}
\hline S. No & Name & Structure & References \\
\hline 1 & Luteolin.7-glucoside (Cynaroside) & & {$[29,43]$} \\
\hline 2 & Luteolin & & {$[29,40,43]$} \\
\hline 3 & Rutin & & {$[29,42,43]$} \\
\hline
\end{tabular}




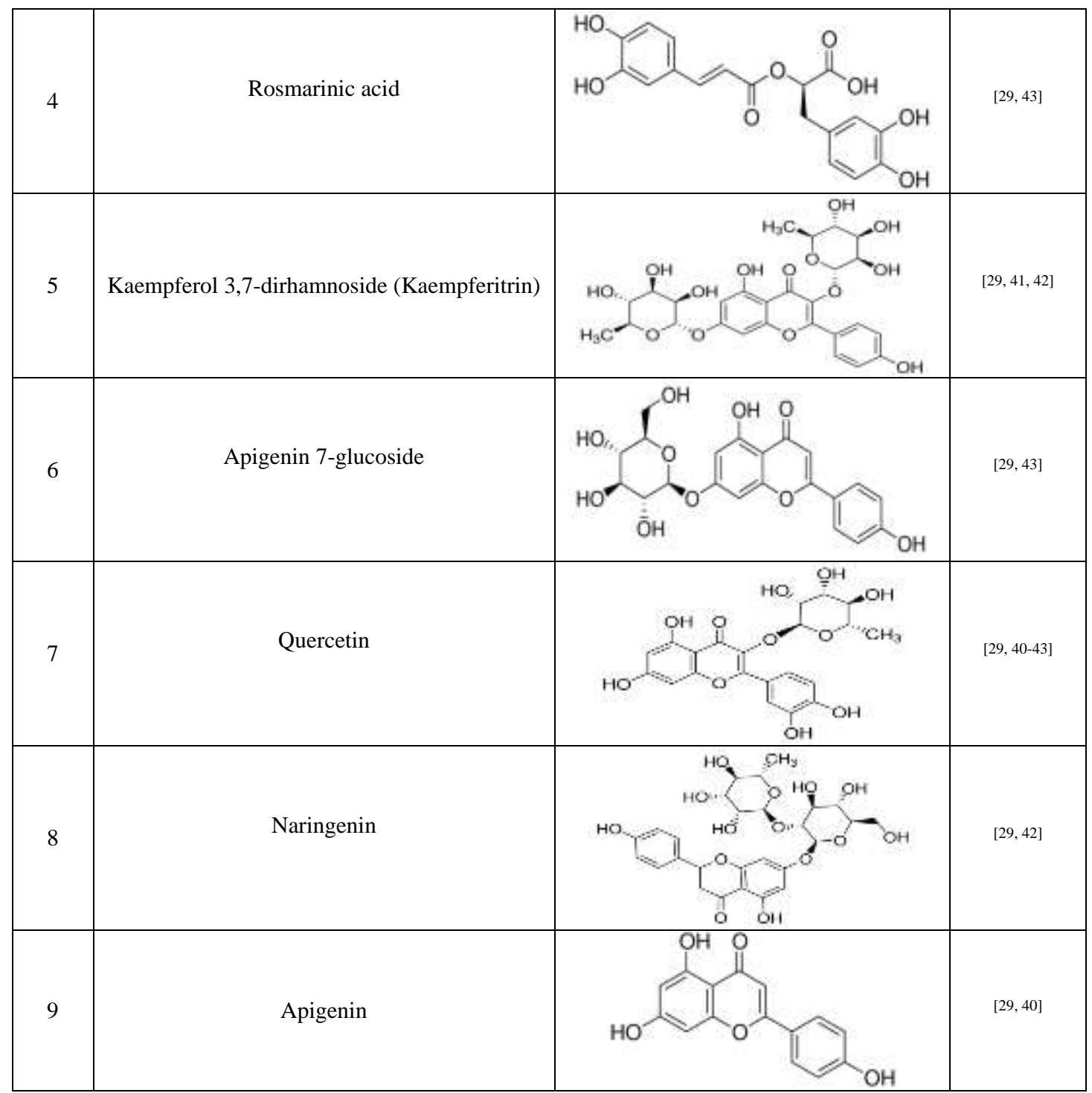

\section{Pharmacological activity}

The plant is reported for antimicrobial [31], anticonvulsant ${ }^{[44]}$, analgesic [45], anti-inflammatory [46], antiulcer, gastric antisecretory [47], antidiabetic [48], nephroprotective [49], hepatoprotective [29], antitumor [29], anticancer [50], antispasmodic, antithrombotic, hypocholesterolemic, antiallergic [51], antiserotonergic, anticholinergic [52], antioxidant, larvicidal, immunomodulatory ${ }^{[53]}$ activities and other beneficial activities.

\subsection{Antimicrobial property}

Ginger shows antibacterial property against so many grampositive and the gram-negative bacteria; (Table 4) namely, Escherichia (E) coli, Staphylococcus (St) aureus, St. epidermidis, Klebsiella (K) pneumoniae, Enterococcus (En) faecalis, Salmonella (Sl) typhi, Sl. typhimurium, Pseudomonas (Ps) aeruginosa, Proteus (Pr) sp., Bacillus (Bc) cereus, Bc. subtilis, Bc. megaterium and Streptococcus (S) faecalis ${ }^{[13]}$. Rampogu et al. studied that gingerenone-A and shogaol have a potential St. aureus encodes a unique enzyme, 6-hydroxymethyl-7,8-dihydropterin pyrophosphokinase inhibitors ${ }^{[54]}$. Noori et al. indicated that the nanoemulsion- loaded coating solution has potent antimicrobial activity comparable to gentamicin antibiotic ${ }^{[31]}$. According to Mostafa, 2018, volatile oil nanoemulsion formulation was stable and effective on S. mutans ${ }^{[55]}$. In another study, the ethanol extract showed considerable activity on Ps. aeruginosa, $B c$. subtilis with zones of inhibition ranging from $7 \pm 0.4 \mathrm{~mm}$ at a concentration of $6.25 \mathrm{mg} / \mathrm{ml}$ to $23.0 \pm 3.2 \mathrm{~mm}$ at $100 \mathrm{mg} / \mathrm{ml}$ and MIC ranging from $6.25 \mathrm{mg} / \mathrm{ml}$ to $12.5 \mathrm{mg} / \mathrm{ml}$ against $B c$. subtilis and Candida albicans. The activity of the aqueous extract was very minimal at low concentrations, but marked activity was observed at higher concentrations ${ }^{[56]}$.

In another research, the Antimicrobial potency of fresh, natural, and commercial dried $Z O$ extracts had been investigated against seven local clinical bacterial isolates by the agar disc diffusion method. The result shows that ZO's chloroform and diethyl ether extracts showed a more significant inhibition zone of tested pathogens except $P$. aeruginosa and $E$. coli ${ }^{[57]}$. The Methanolic extract of $Z O$ was assayed in vitro for antibacterial activity by using the agar diffusion method. The zone of inhibition was compared with different standard antibiotics. The result showed good antibacterial activity ${ }^{[58]}$. 
Table 4: Antimicrobial activity of $Z O$

\begin{tabular}{|c|c|c|c|c|c|c|c|c|c|c|}
\hline $\begin{array}{l}\text { S. } \\
\text { no }\end{array} \mid$ & Activity & Type of extract/ & concentration & Components & models/method & Tested organism & $\begin{array}{c}\text { The diameter } \\
\text { of the } \\
\text { inhibition zone }\end{array}$ & \begin{tabular}{|c|} 
Minimal \\
inhibitory \\
Concentration \\
(MIC)
\end{tabular} & Positive Controls & Ref. \\
\hline 1 & Antibacterial & Silver nanoparticle & $\begin{array}{c}500 \mu \mathrm{g} / \mathrm{mL} \text { to } \\
1.95 \mu \mathrm{g} / \mathrm{mL}\end{array}$ & ------------ & $\begin{array}{l}\text { Agar well diffusion } \\
\text { assay, } 96 \text { well } \\
\text { microtiter plate assay }\end{array}$ & S. aureus and E. coli & $16-19 \mathrm{~mm}$ & $62.5-125 \mu \mathrm{g} / \mathrm{mL}$ & --------------- & [59] \\
\hline 2 & Antibacterial & $\begin{array}{l}\text { Silver nanoparticle } \\
\text { from ginger extract }\end{array}$ & $0.8-50 \mu \mathrm{g} / \mathrm{mL}$ & ------------ & $\begin{array}{c}\text { agar well diffusion } \\
\text { method, broth dilution } \\
\text { assay }\end{array}$ & \begin{tabular}{|c|} 
Vibrio $(V)$ anguillarum, $V$. \\
alginolyticus, Aeromonas punctata, \\
V.parahaemolyticus, V. splendidus, \\
and V. harveyi
\end{tabular} & $\begin{array}{c}11.1 \pm 0.02- \\
15.8 \pm 0.05 \mathrm{~mm}\end{array}$ & $0.4-6.5 \mu \mathrm{g} / \mathrm{mL}$ & $106 \mathrm{CFU} / \mathrm{mL}$ bacterial suspensions & {$[60]$} \\
\hline 3 & Antibacterial & $\begin{array}{l}\text { Leaves essential } \\
\text { oil nano emulsion }\end{array}$ & $100 \mu \mathrm{l}$ & $\begin{array}{l}\beta \text {-pinene }(8.59 \%) \text {, terpinolene } \\
(7.46 \%), \delta \text {-Cadinene }(7.05 \%)\end{array}$ & $\begin{array}{c}\text { Agar diffusion method, } \\
\text { Broth microdilution } \\
\text { method }\end{array}$ & S. mutans ATCC 25175 & $25 \pm 1.0 \mathrm{~mm}$ & $62.5 \mu \mathrm{l} / \mathrm{mL}$ & Clindamycin $2 \mu \mathrm{g} / \mathrm{disc}$ & [55] \\
\hline 4 & Antibacterial & ethanolic & -------- & ---------- & $\begin{array}{c}\text { In vitro /microdilution } \\
\text { method }\end{array}$ & $\begin{array}{l}\text { St. aureus, Bc. subtilis, Bc. cereus, } \\
\text { Ps.aeruginosa, Pr. mirabilis, E. coli, } \\
\text { Sl. enterica and Sl. typhimurium }\end{array}$ & ---------- | & $0.0024->20 \mu \mathrm{g} / \mathrm{ml}$ & Tetracycline & [61] \\
\hline 5 & Antibacterial & Methanolic & $\mid 0.78-100 \mu \mathrm{g} / \mathrm{ml}$ & 6-,8-, 10-gingerol and 6-shogoal & $\begin{array}{l}\text { In vitro/agar dilution } \\
\text { method }\end{array}$ & Helicobacter pylori & --------- & $6.25-50 \mu \mathrm{g} / \mathrm{ml}$ & Amoxicillin & [62] \\
\hline 6 & Antibacterial & methanolic & ----- & \begin{tabular}{|c|} 
Octanal, 2-Naphthale \\
Namine, Endo-Borneol, Decanal, \\
1,2-15,16-Diepoxyhexadecane, \\
Propanal,2-methyl-3-phenyl, \\
Benzeneacetic \\
acid ,4-(1H-1,2,3,4-tetrazol-1-yl), \\
Ascaridole epoxide etc \\
\end{tabular} & $\begin{array}{l}\text { Muller-Hinton agar } \\
\text { plates }\end{array}$ & $\begin{array}{c}\text { Ps.eurogenosa, E. coli, K. } \\
\text { pneumonia, St. aureus, Pr. mirabilis }\end{array}$ & $\mid \begin{array}{c}1.99 \pm 0.200- \\
4.93 \pm 0.290 \mathrm{~mm}\end{array}$ & 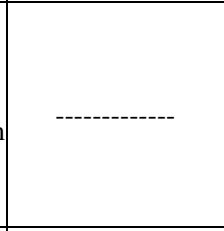 & Streptomycin, Rifampin, Cefotaxime & [58] \\
\hline 7 & Antibacterial & ginger extract & $\begin{array}{c}0.001-0.6 \\
\mathrm{mg} / \mathrm{mL}\end{array}$ & ---------- & $\begin{array}{l}\text { Solid blood agar } \\
\text { culture medium }\end{array}$ & S. mutans and S. sanguinis & ---------- & $0.02-0.3 \mathrm{mg} / \mathrm{mL}$ & ---------- & [63] \\
\hline 8 & Antibacterial & Boiled ginger extract & ------------ & ------------- & Agar diffusion assay & $\begin{array}{c}\text { E. coli, Ps.aeruginosa, St. aureus, } \\
\text { Vibrio cholerae, K. spp., and Sl. } \\
\text { species }\end{array}$ & $\begin{array}{c}8.0 \pm 1.73- \\
11.67 \pm 1.53 \\
\mathrm{~mm}\end{array}$ & -------------- & Gentamicin & [6] \\
\hline 9 & Antibacterial & Essential oil & $\begin{array}{c}0.04-5 \\
\mathrm{mg} / \mathrm{mL}\end{array}$ & --------- & $\begin{array}{l}\text { Broth Microdilution } \\
\text { Assays }\end{array}$ & En. faecalis & ------ & $0.31 \mathrm{mg} / \mathrm{mL}$ & $\begin{array}{c}\text { Amoxicillin or } \\
\text { ampicillin and 2.5\% sodium hypochlorite }\end{array}$ & [64] \\
\hline 10 & Antibacterial & \begin{tabular}{|c} 
Nano emulsion-based \\
edible sodium caseinate \\
coating containing \\
ginger essential oil \\
\end{tabular} & $\begin{array}{c}3 \%, 6 \% \text { of } \\
\text { essential oil }\end{array}$ & $\begin{array}{c}\alpha \text {-zingiberene, } \beta \text { - } \\
\text { sesquiphellandrene }\end{array}$ & $\begin{array}{l}\text { agar well diffusion } \\
\text { assay, paper disc } \\
\text { method }\end{array}$ & $\begin{array}{l}\text { Listeria monocytogenes, Sl. } \\
\text { typhimurium (ATTC 14028) }\end{array}$ & $\begin{array}{c}(8.66 \pm 0.94 \\
\mathrm{mm} \text { and } 10.33 \\
\pm 0.93 \mathrm{~mm}\end{array}$ & ---------- & Chloramphenicol and gentamicin & [31] \\
\hline 11 & Antibacterial & ethanolic extract & -------- & ---------- & $\begin{array}{l}\text { Cup- Plate Agar } \\
\text { Diffusion Method, } \\
\text { macro broth dilution } \\
\text { methods }\end{array}$ & $\begin{array}{c}\text { St. aureus, Pr. mirabilis, } \\
\text { Ps.aeruginosa, K. pneumoniae, E. } \\
\text { coli }\end{array}$ & $17-19 \mathrm{~mm}$ & $3.3-12.5 \%$ & -------- & {$[65]$} \\
\hline 12 & Antibacterial & Methanol extract & $25-100 \mu \mathrm{g} / \mathrm{mL}$ & -------- & $\begin{array}{l}\text { Agar-well diffusion } \\
\text { method, broth } \\
\text { microdilution method }\end{array}$ & $\begin{array}{l}\text { Ps.aeruginosa, K. pneumonia, Sl. } \\
\text { typhi, St. aureus, E. coli }\end{array}$ & $\begin{array}{c}15.08 \pm 0.20- \\
26.03 \pm 0.41 \\
\mathrm{~mm}\end{array}$ & $12.5-25 \mu \mathrm{g} / \mathrm{mL}$ & --------- & [66] \\
\hline 13 & Antibacterial & $\begin{array}{c}\text { Methanol: Water (70: } \\
30)\end{array}$ & $1-200 \mathrm{mg} / \mathrm{ml}$ & -.---------- & $\begin{array}{l}\text { agar well diffusion } \\
\text { method }\end{array}$ & P. aeruginosa & $\begin{array}{c}27.09 \pm 0.003 \\
\mathrm{~mm}\end{array}$ & $10 \mu \mathrm{g} / \mathrm{ml}$ & Amikacin & [67] \\
\hline
\end{tabular}




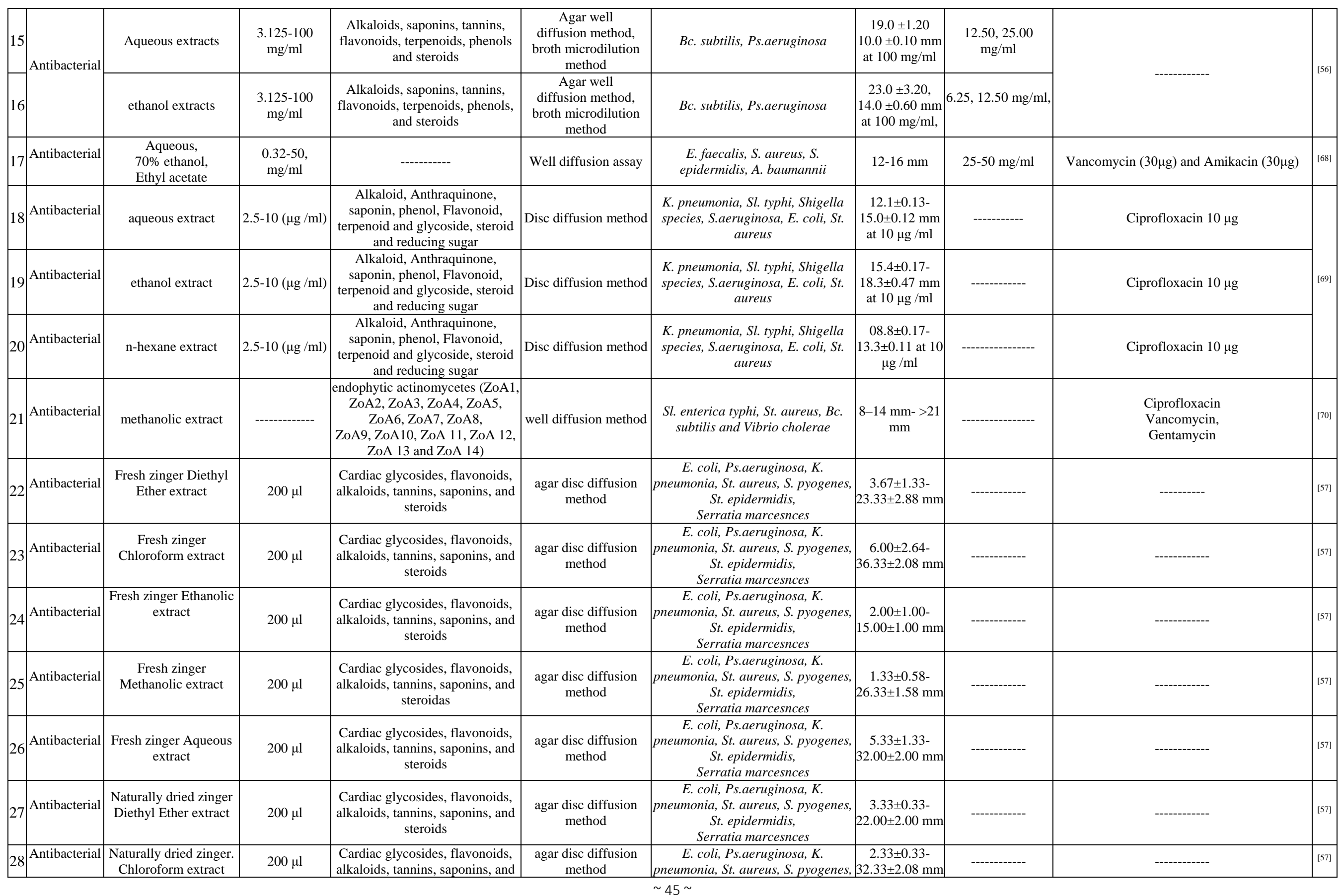




\begin{tabular}{|c|c|c|c|c|c|c|c|c|c|c|}
\hline & & & & steroids & & $\begin{array}{c}\text { St. epidermidis, } \\
\text { Serratia marcesnces }\end{array}$ & & & & \\
\hline 29 & Antibacterial & $\begin{array}{c}\text { Naturally dried zinger. } \\
\text { Ethanolic extract }\end{array}$ & $200 \mu \mathrm{l}$ & $\begin{array}{c}\text { Cardiac glycosides, flavonoids, } \\
\text { alkaloids, tannins, saponins, and } \\
\text { steroids }\end{array}$ & $\begin{array}{l}\text { agar disc diffusion } \\
\text { method }\end{array}$ & \begin{tabular}{|c|} 
E. coli, Ps.aeruginosa, $K$. \\
pneumonia, St. aureus, S. pyogenes, \\
St. epidermidis, \\
Serratia marcesnces
\end{tabular} & $\begin{array}{c}0.00 \pm 0.00- \\
35.67 \pm 2.08 \mathrm{~mm}\end{array}$ & & & [57] \\
\hline 30 & Antibacterial & $\begin{array}{c}\text { Naturally dried zinger. } \\
\text { Methanolic extract }\end{array}$ & $200 \mu \mathrm{l}$ & $\begin{array}{c}\text { Cardiac glycosides, flavonoids, } \\
\text { alkaloids, tannins, saponins, and } \\
\text { steroids }\end{array}$ & $\begin{array}{l}\text { agar disc diffusion } \\
\text { method }\end{array}$ & \begin{tabular}{|c|} 
E. coli, Ps.aeruginosa, $K$. \\
pneumonia, St. aureus, S. pyogenes, \\
St. epidermidis, \\
Serratia marcesnces \\
\end{tabular} & \begin{tabular}{|c|}
$2.00 \pm 1.00-$ \\
$27.67 \pm 2.51 \mathrm{~mm}$
\end{tabular} & & & [57] \\
\hline 31 & Antibacterial & $\begin{array}{l}\text { commercially dried } \\
\text { zinger Diethyl Ether } \\
\text { extract }\end{array}$ & $200 \mu \mathrm{l}$ & $\begin{array}{l}\text { Cardiac glycosides, flavonoids, } \\
\text { alkaloids, tannins, saponins, and } \\
\text { steroids }\end{array}$ & $\begin{array}{l}\text { agar disc diffusion } \\
\text { method }\end{array}$ & \begin{tabular}{|c|} 
E. coli, Ps.aeruginosa, $K$. \\
pneumonia, St. aureus, S. pyogenes, \\
St. epidermidis, \\
Serratia marcesnces \\
\end{tabular} & $\begin{array}{c}1.33 \pm 0.33- \\
32.00 \pm 2.00 \mathrm{~mm}\end{array}$ & & & [57] \\
\hline 32 & Antibacterial & $\begin{array}{l}\text { Commercially dried } \\
\text { zinger. Chloroform } \\
\text { extract }\end{array}$ & $200 \mu \mathrm{l}$ & $\begin{array}{c}\text { Cardiac glycosides, flavonoids, } \\
\text { alkaloids, tannins, saponins, and } \\
\text { steroids }\end{array}$ & $\begin{array}{l}\text { agar disc diffusion } \\
\text { method }\end{array}$ & \begin{tabular}{|c|} 
E. coli, Ps.aeruginosa, $K$. \\
pneumonia, St. aureus, S. pyogenes, \\
St. epidermidis, \\
Serratia marcesnces \\
\end{tabular} & \begin{tabular}{|c|}
$2.00 \pm 1.00-$ \\
$30.00 \pm 1.00 \mathrm{~mm}$
\end{tabular} & & & [57] \\
\hline 33 & Antibacterial & $\begin{array}{c}\text { Commercially dried } \\
\text { zinger Ethanolic extract }\end{array}$ & $200 \mu \mathrm{l}$ & $\begin{array}{c}\text { Cardiac glycosides, flavonoids, } \\
\text { alkaloids, tannins, saponins, and } \\
\text { steroids }\end{array}$ & $\begin{array}{l}\text { agar disc diffusion } \\
\text { method }\end{array}$ & \begin{tabular}{|c|} 
E. coli, Ps.aeruginosa, $K$. \\
pneumonia, St. aureus, S. pyogenes, \\
St. epidermidis, \\
Serratia marcesnces
\end{tabular} & $\left|\begin{array}{c}1.33 \pm 0.33- \\
20.67 \pm 1.58 \mathrm{~mm}\end{array}\right|$ & & & [57] \\
\hline 34 & Antibacterial & $\begin{array}{l}\text { Commercially dried } \\
\text { zinger. Methanolic } \\
\quad \text { extract }\end{array}$ & $200 \mu 1$ & $\begin{array}{c}\text { Cardiac glycosides, flavonoids, } \\
\text { alkaloids, tannins, saponins, and } \\
\text { steroids }\end{array}$ & $\begin{array}{l}\text { agar disc diffusion } \\
\text { method }\end{array}$ & \begin{tabular}{|c|} 
E. coli, Ps.aeruginosa, $K$. \\
pneumonia, St. aureus, v pyogenes, \\
St. epidermidis, \\
Serratia marcesnces \\
\end{tabular} & \begin{tabular}{|c|}
$2.00 \pm 1.00-$ \\
$30.33 \pm 1.58 \mathrm{~mm}$
\end{tabular} & & & [57] \\
\hline 35 & Antibacterial & Ethanol Extract & . & $\begin{array}{l}\text { saponins, tannins, alkaloids and } \\
\text { flavonoids }\end{array}$ & agar diffusion method & $\begin{array}{c}\text { St. aureus, Bc. subtilis, Pr. } \\
\text { mirabilis, Ps.aeruginosa, E. coli, Sl. } \\
\text { typhi }\end{array}$ & $0.00-13.00 \mathrm{~mm}$ & & \multirow{2}{*}{\begin{tabular}{|c|} 
Nitrofurantoin, Augmentin, Norfloxacin, \\
Tetracycline Gentamycin, Ciprofloxacin, \\
Chloramphenicol, Ampicillin, Nalidixic acid, \\
Cefuroxime, Drovid, Cephalexin, \\
Erythromycin, Clindamycin, Septrin, Amoxil, \\
Amplicox
\end{tabular}} & \multirow{2}{*}{ [9] } \\
\hline 36 & Antibacterial & Aqueous Extract & & $\begin{array}{c}\text { saponins, tannins, alkaloids and } \\
\text { flavonoids }\end{array}$ & agar diffusion method & $\begin{array}{c}\text { St. aureus, Bc. subtilis, } P r . \\
\text { mirabilis, Ps.aeruginosa, E. coli and } \\
\text { Sl. typhi }\end{array}$ & $0.00-17.00 \mathrm{~mm}$ & & & \\
\hline 37 & \begin{tabular}{|c|}
$\begin{array}{c}\text { Antifungal } \\
\text { activity }\end{array}$ \\
\end{tabular} & methanolic extract & ---------- & Endophytic actinomycetes & well diffusion method & Pythium myriotylum & $1-14 \mathrm{~mm}$ & ---------' & & [70] \\
\hline 38 & $\begin{array}{c}\text { Antifungal } \\
\text { activity }\end{array}$ & Aqueous & $\begin{array}{l}3.125-100 \\
\mathrm{mg} / \mathrm{ml}\end{array}$ & $\begin{array}{c}\text { Alkaloids, saponins, tannins, } \\
\text { flavonoids, terpenoids, phenols, } \\
\text { and steroids }\end{array}$ & $\begin{array}{l}\text { Agar well diffusion } \\
\text { method, broth } \\
\text { microdilution method }\end{array}$ & $\begin{array}{l}\text { Aspergillus flavus and Candida } \\
\text { albicans }\end{array}$ & $18.0 \pm 1.30 \mathrm{~mm}$ & $6.25 \mathrm{mg} / \mathrm{ml}$ & --------- & \multirow{2}{*}[56]{} \\
\hline 39 & $\begin{array}{c}\text { Antifungal } \\
\text { activity }\end{array}$ & ethanol extracts & $\begin{array}{c}3.125-100 \\
\mathrm{mg} / \mathrm{ml}\end{array}$ & $\begin{array}{c}\text { Alkaloids, saponins, tannins, } \\
\text { flavonoids, terpenoids, phenols, } \\
\text { and steroids }\end{array}$ & $\begin{array}{l}\text { Agar well diffusion } \\
\text { method, broth } \\
\text { microdilution method }\end{array}$ & $\begin{array}{l}\text { Aspergillus flavus and Candida } \\
\text { albicans }\end{array}$ & $19 \pm 1.80 \mathrm{~mm}$ & $6.25 \mathrm{mg} / \mathrm{ml}$ & -------- & \\
\hline 40 & $\begin{array}{c}\text { Antifungal } \\
\text { activity }\end{array}$ & Essential oil & $\begin{array}{c}0.0625 \text { to } 2.0 \\
\mathrm{mg} / \mathrm{mL}\end{array}$ & $\begin{array}{c}\text { Eudesmol }(8.19 \%), \gamma \text {-terpinene } \\
(7.88 \%), \alpha \text {-curcumene }(7.28 \%), \\
\text { alloaromadendrene }(6.56 \%) \\
\text { zingiberene }(6.06 \%) \\
\end{array}$ & $\begin{array}{l}\text { inhibition of radial } \\
\text { growth, 24-well plates } \\
\text { for filamentous fungi, }\end{array}$ & $\begin{array}{c}\text { A. niger, } F . \text { moniliforme, } F . \\
\text { sporotrichum and } T \text {. entagrophytes }\end{array}$ & ----------- & $\begin{array}{l}\text { FC50 value: } 0.08- \\
1.5 \mathrm{mg} / \mathrm{mL}\end{array}$ & Ketoconazole $(60 \mu \mathrm{g})$ & [12] \\
\hline 41 & $\begin{array}{c}\text { Antifungal } \\
\text { activity }\end{array}$ & Essential oil & $\begin{array}{c}0.0625 \text { to } 2.0 \\
\mathrm{mg} / \mathrm{mL}\end{array}$ & $\begin{array}{c}\text { Eudesmol }(8.19 \%), \gamma \text {-terpinene } \\
(7.88 \%), \alpha \text {-curcumene }(7.28 \%), \\
\text { alloaromadendrene }(6.56 \%) \\
\text { zingiberene }(6.06 \%)\end{array}$ & $\begin{array}{c}\text { Kirby-Bauer agar } \\
\text { diffusion method, 24- } \\
\text { well plates for yeast } \\
\text { fungi, }\end{array}$ & $\begin{array}{c}\text { C. albicans } 17 M R \text {, C. tropicalis and } \\
\text { C. glabrata }\end{array}$ & $\mid \begin{array}{c}14.50 \pm 12.12 \\
\text { to } 30.00 \pm 0.00 \\
\mathrm{~mm}\end{array}$ & $0.25-0.75 \mathrm{mg} / \mathrm{mL}$ & Nystatin $(30 \mu \mathrm{g} /$ disc $)$ & [12] \\
\hline
\end{tabular}




\section{Discussion}

The study result highlights the usefulness of $Z O$ in treating microbial diseases and the need to improve their utilisation in this respect. It is especially urgent when considering the growth rate of multi-resistant drug strains of bacteria increases worldwide ${ }^{[9]}$. Different in vitro and in vivo experiments were performed to determine the efficacy of essential oil, oleoresins, and extracts obtained from ginger against bacteria and fungi. It is well known that the antimicrobial activity of essential oil, extracts, and oleoresins depends primarily on their chemical composition, the solvent extraction, the methods used to obtain it, and the procedure to which the ginger has been submitted ${ }^{[22]}$. The chemical constituents of oils and their antimicrobial activity tend to be related ${ }^{[14]}$. Sesquiterpenoids and phenolic compounds (eugenol, shogaols, zingerone, gingerdiols, gingerols, etc.) are assumed to be responsible for the marked antimicrobial activity of essential oils and oleoresins. However, the overall efficiency of essential oils and oleoresins is likely to benefit from the synergistic action of all constituents ${ }^{[8,9]}$. Generally speaking, the extract of the antimicrobial mechanism of essential oils has not been completely elucidated. However, lipophilicity or hydrophobicity of essential oils have been suggested to play an important role in antimicrobial activity, which allow them to partition between lipids of the bacterial or fungal cell membrane and mitochondria, disturbing the cell structures and interpreting them more permeable, which will lead to cell death ${ }^{[14]}$. A higher concentration of oxygenated compounds, such as geranial, 1,8-cineole, neral, borneol, alpha-terpineol, was also found in ginger's essential oil. Besides, oxygenated compounds can cause leakages of critical molecules and inhibit respiration and transport of ions. Therefore, these compounds may have many ways of influencing microbial cells, resulting in their inhibition ${ }^{[22]}$.

\section{Conclusion}

Many chemical constituents, essential oil, and extracts of Ginger are reported for antimicrobial, anticonvulsant, analgesic, anti-inflammatory, antiulcer, gastric antisecretory, antidiabetic, nephroprotective, hepatoprotective, antitumor, anticancer, antispasmodic, antithrombotic, hypocholesterolemic, antiallergic, antiserotonergic, anticholinergic, antioxidant, larvicidal, immunomodulatory activities and other beneficial activities.

Based on our observations on ginger's antimicrobial activities, it can be said that ginger has marked antibacterial properties. It has been shown in the development of this study that ginger has many bioactive compounds that can be obtained as an essential oil, extract, and oleoresins. Some of these compounds, because of their extensive antibacterial and antifungal inhibitory range, can inhibit the most important pathogens associated with foodborne diseases. The research showed that ginger have potent antimicrobial activity and can be applied in various research areas, such as the pharmaceutical and food industries.

\section{Acknowledgement}

The author is thankful to the library staff of NIUM for providing all kinds of literature related to this manuscript at the time of writing.

\section{Conflict of interest}

There is no conflict of interest to declare.

\section{References}

1. Mazzei R, Leonti M, Spadafora S, Patitucci A. A review of the antimicrobial potential of herbal drugs used in popular Italian medicine $(1850 \mathrm{~s}-1950 \mathrm{~s})$ to treat bacterial skin diseases Rosalucia. J Ethnopharmacol 2019.

2. Balouiri M, Sadiki M, Ibnsouda SK. Methods for in vitro evaluating antimicrobial activity: A review. J Pharm Anal 2016;6(2):71-9.

3. Aleem M. Anti-Inflammatory and Anti-Microbial Potential of Plumbago zeylanica L.: A Review. J Drug Deliv Ther [Internet] 2020;10(5-s):229-35. Available from:

http://jddtonline.info/index.php/jddt/article/view/4445

4. Antibiotic resistance [Internet]. [cited 2020 Sep 16];Available from: https://www.who.int/newsroom/fact-sheets/detail/antibiotic-resistance

5. Aleem M, Imran Khan M, Islam Usmani Q, Ahmad A. Review on Darunaj-aqrabi (Doronicum hookeri C.B. Clarke): an Unexplored Medicinal Plant of Unani System of Medicine. J AYUSH Ayurveda, Yoga,Unani ,Siddha Homeopath [Internet] 2020;9(2):41-52. Available from: http://medicaljournals.stmjournals.in/index.php/JoAYUS $\mathrm{H} /$ article/view/2108

6. Islam K, Rowsni AA, Khan M, Kabir S. Antimicrobal Activity of Ginger (Zingiber Officinale) Extracts Against Food-Borne Pathogenic Bacteria. Int $\mathbf{J}$ Sci Environ Technol 2014;3(3):867-71.

7. Aleem M, Ahmad E, Anis M. Botany, phytochemistry, pharmacology and Unani traditional uses of Jadwar (Delphinium denudatum Wall.): A Review. J Phytopharm [Internet] 2020;9(5):378-83. Available from: http://www.phytopharmajournal.com/Volume9issue5.htm 1\#

8. Singh G, Kapoor IPS, Singh P, de Heluani CS, de Lampasona MP, Catalan CAN. Chemistry, antioxidant and antimicrobial investigations on essential oil and oleoresins of Zingiber officinale. Food Chem Toxicol 2008;46(10):3295-302.

9. Akintobi O, Onoh C, Ogele J, Idowu A, Ojo O, Okonko I. Antimicrobial Activity Of Zingiber Officinale (Ginger) Extract Against Some Selected Pathogenic Bacteria. Nat Sci 2013.

10. dan Singh DSPSSSVBSP. Ginger (Zingiber officinale): A Nobel Herbal Remedy. Int.J.Curr.Microbiol.App.Sci, 7, 065-4077. Int J Curr Microbiol Appl Sci 2018;7(7):4065-77.

11. Mbaveng AT, Kuete V. Zingiber officinale. Med Spices Veg from Africa Ther Potential Against Metab Inflammatory, Infect Syst Dis 2017,627-39.

12. López EIC, Balcázar MFH, Mendoza JMR, Ortiz ADR, Melo MTO, Parrales RS et al. Antimicrobial Activity of Essential Oil of \&lt;i\&gt;Zingiber officinale\&lt;/i\&gt; Roscoe (Zingiberaceae). Am J Plant Sci 2017;08(07):1511-24.

13. Abdalla WE, Abdallah EM. Antibacterial Activity of Ginger (Zingiber Officinale Rosc.) Rhizome: A Mini Review. Int $\mathrm{J}$ Pharmacogn Chinese Med [Internet] 2018;2(4):000142. Available from: https://www.researchgate.net/publication/325999178

14. El-baky HHA, El-Baroty GS, Farag RS, Saleh Ma. Characterization of antioxidant and antimicrobial compounds of cinnamon and ginger essential oils. African J Biochem Res 2010;4(6):167-74.

15. Baruah J, Pandey SK, Begum T, Sarma N, Paw M, Lal M. Molecular diversity assessed amongst high dry rhizome recovery Ginger germplasm (Zingiber officinale Roscoe) from NE-India using RAPD and ISSR markers. 
Ind Crops Prod 2019;129(2018):463-71.

16. Syafitri DM, Levita J, Mutakin M, Diantini A. A Review: Is Ginger (Zingiber officinale var. Roscoe) Potential for Future Phytomedicine? Indones J Appl Sci 2018;8(1):813.

17. Panpatil VV, Tattari S, Kota N, Nimgulkar C, Polasa K. In vitro evaluation on antioxidant and antimicrobial activity of spice extracts of ginger, turmeric and garlic. 2Ginger, 1Turmeric, 3Garlic (E. Coli, Salmonella) 2013;2(3):143-8.

18. Pan D, Zeng C, Zhang W, Li T, Qin Z, Yao X et al. Nonvolatile pungent compounds isolated from: Zingiber officinale and their mechanisms of action. Food Funct 2019;10(2):1203-11.

19. Akbar S. Handbook of 200 Medicinal Plants [Internet]. Cham: Springer International Publishing; 2020. Available from: http://link.springer.com/10.1007/978-3-030-168070

20. Khan A, Muhit Azam. New Delhi (India): Central Council for Research in Unani Medicine, Department of AYUSH, Ministry of Health and Family Welfare, Government of India, 2013, 02.

21. Ghani M, Khazainul Advia. (Urdu). New Delhi (India): Idara Kitab al Shifa, 2011.

22. Beristain-Bauza SDC, Hernández-Carranza P, Cid-Pérez TS, Ávila-Sosa R, Ruiz-López II, Ochoa-Velasco CE. Antimicrobial Activity of Ginger (Zingiber Officinale) and Its Application in Food Products. Food Rev Int 2019;35(5):407-26.

23. da Silveira Vasconcelos M, Mota EF, Gomes-Rochette NF, Nunes-Pinheiro DCS, Nabavi SM, de Melo DF. Ginger (Zingiber officinale Roscoe) [Internet]. In: Nonvitamin and Nonmineral Nutritional Supplements. Elsevier 2019, 235-9.Available from: https://linkinghub.elsevier.com/retrieve/pii/B9780128124 918000345

24. Yeh H Yu, Chuang C Hung, Chen H Chun, Wan C Jen, Chen $\mathrm{T}$ liang, Lin $\mathrm{L}$ yun. Bioactive components analysis of two various gingers (Zingiber officinale Roscoe) and antioxidant effect of ginger extracts. LWT - Food Sci Technol 2014;55(1):329-34

25. Gong F, Fung YS, Liang YZ. Determination of volatile components in ginger using gas chromatography-mass spectrometry with resolution improved by data processing techniques. J Agric Food Chem 2004;52(21):6378-83.

26. Singh G, Maurya S, Catalan C, de Lampasona MP. Studies on essential oils, part 42: Chemical, antifungal, antioxidant and sprout suppressant studies on ginger essential oil and its oleoresin. Flavour Fragr J 2005;20(1):1-6.

27. Yu Y, Huang T, Yang B, Liu X, Duan G. Development of gas chromatography-mass spectrometry with microwave distillation and simultaneous solid-phase microextraction for rapid determination of volatile constituents in ginger. J Pharm Biomed Anal 2007;43(1):24-31.

28. Sharma PK, Singh V, Ali M. Chemical composition and antimicrobial activity of fresh rhizome essential oil of zingiber officinale roscoe. Pharmacogn J 2016;8(3):18590.

29. Fahmi A, Hassanen N, Abdur-Rahman M, Shams-Eldin E. Phytochemicals, antioxidant activity and hepatoprotective effect of ginger (Zingiber officinale) on diethylnitrosamine toxicity in rats. Biomarkers
2019;24(5):436-47.

30. Yamamoto-Ribeiro MMG, Grespan R, Kohiyama CY, Ferreira FD, Mossini SAG, Silva EL et al. Effect of Zingiber officinale essential oil on Fusarium verticillioides and fumonisin production. Food Chem [Internet] 2013;141(3):3147-52. Available from: https://linkinghub.elsevier.com/retrieve/pii/S0308814613 007528

31. Noori S, Zeynali F, Almasi H. Antimicrobial and antioxidant efficiency of nanoemulsion-based edible coating containing ginger (Zingiber officinale) essential oil and its effect on safety and quality attributes of chicken breast fillets. Food Control 2018;84:312-20.

32. Zancan KC, Marques MOM, Petenate AJ, Meireles MAA. Extraction of ginger (Zingiber officinale roscoe) oleoresin with $\mathrm{CO} 2$ and co-solvents: A study of the antioxidant action of the extracts. J Supercrit Fluids 2001;24(1):57-76.

33. Mesomo MC, Corazza ML, Ndiaye PM, Dalla Santa OR, Cardozo L, Scheer ADP. Supercritical CO2 extracts and essential oil of ginger (Zingiber officinale R.): Chemical composition and antibacterial activity. J Supercrit Fluids 2013;80:44-9.

34. Chen BH, Wu PY, Chen KM, Fu TF, Wang HM, Chen CY. Antiallergic potential on RBL-2H3 cells of some phenolic constituents of Zingiber officinale (ginger). J Nat Prod 2009;72(5):950-3.

35. Shan B, Cai YZ, Sun M, Corke H. Antioxidant capacity of 26 spice extracts and characterization of their phenolic constituents. J Agric Food Chem 2005;53(20):7749-59.

36. Tanaka K, Arita M, Sakurai H, Ono N, Tezuka Y. Analysis of Chemical Properties of Edible and Medicinal Ginger by Metabolomics Approach. Biomed Res Int 2015, 2015.

37. Gabr SA, Alghadir AH, Ghoniem GA. Biological activities of ginger against cadmium-induced renal toxicity. Saudi J Biol Sci 2019;26(2):382-9.

38. Dharmesh SM, Nanjundaiah SM, Annaiah HNM. Gastroprotective effect of ginger rhizome (Zingiber officinale) extract: Role of gallic acid and cinnamic acid in $\mathrm{H}+, \mathrm{K}+-\mathrm{ATPase} / \mathrm{H}$. pylori inhibition and antioxidative mechanism. Evidence-based Complement Altern Med 2011.

39. Ghasemzadeh A, Jaafar HZE, Rahmat A. Antioxidant activities, total phenolics and flavonoids content in two varieties of malaysia young ginger (Zingiber officinale Roscoe). Molecules 2010;15(6):4324-33.

40. Ghasemzadeh A, Ghasemzadeh N. Effects of shading on synthesis and accumulation of polyphenolic compounds in ginger (Zingiber officinale Roscoe) varieties. J Med Plants Res 2011;5(11):2435-42.

41. Ali Ghasemzadeh. Effect of salicylic acid application on biochemical changes in ginger (Zingiber officinale Roscoe). J Med Plants Res 2012;6(5):790-5.

42. Ghasemzadeh A, Jaafar HZE, Rahmat A. Elevated Carbon Dioxide Increases Contents of Flavonoids and Phenolic Compounds, and Antioxidant Activities in Malaysian Young Ginger (Zingiber officinale Roscoe.) Varieties. Molecules 2010;15(11):7907-22.

43. Fedosov AI, Kyslychenko AA, Gudzenko AV, Semenchenko OM, Kyslychenko VS. The determination of phenolic compounds in garlic extracts by HPLC GC/MS technique. Der Pharma Chem 2016;8(9):118-24.

44. Hosseini A, Mirazi N. Acute administration of ginger (Zingiber officinale rhizomes) extract on timed 
intravenous pentylenetetrazol infusion seizure model in mice. Epilepsy Res 2014;108(3):411-9.

45. Kravchenko I, Eberle L, Nesterkina M, Kobernik A. Anti-inflammatory and analgesic activity of ointment based on dense ginger extract (Zingiber officinale). J HerbMed Pharmacol 2019;8(2):126-32.

46. Ezzat SM, Ezzat MI, Okba MM, Menze ET, Abdel-Naim AB. The hidden mechanism beyond ginger (Zingiber officinale Rosc.) potent in vivo and in vitro antiinflammatory activity. $\mathbf{J}$ Ethnopharmacol 2018;214(2017):113-23.

47. Airaodion AI, Ogbuagu U, Ogbuagu EO, Airaodion EO, Paul A, Oloruntoba AP et al. Investigation of Aqueous Extract of Zingiberofficinale Root Potential in the Prevention of Peptic Ulcer in Albino Rats. Int J Res Innov Appl Sci 2019;IV(II):64-7.

48. Lamuchi-Deli N, Aberomand M, Babaahmadi-Rezaei H, Mohammadzadeh G. Effects of the hydroalcoholic extract of Zingiber officinale on arginase $i$ activity and expression in the retina of streptozotocin-induced diabetic rats. Int J Endocrinol Metab 2017;15(2).

49. Rodrigues FAP, Prata MMG, Oliveira ICM, Alves NTQ, Freitas REM, Monteiro HSA et al. Gingerol fraction from Zingiber officinale protects against gentamicininduced nephrotoxicity. Antimicrob Agents Chemother 2014;58(4):1872-8.

50. Chang JS, Wang KC, Yeh CF, Shieh DE, Chiang LC. Fresh ginger (Zingiber officinale) has anti-viral activity against human respiratory syncytial virus in human respiratory tract cell lines. $\mathrm{J}$ Ethnopharmacol 2013;145(1):146-51.

51. Khan AM, Shahzad M, Raza Asim MB, Imran M, Shabbir A. Zingiber officinale ameliorates allergic asthma via suppression of Th2-mediated immune response. Pharm Biol 2015;53(3):359-67.

52. Sutalangka C, Wattanathorn J. Neuroprotective and cognitive-enhancing effects of the combined extract of Cyperus rotundus and Zingiber officinale. BMC Complement Altern Med 2017;17(1):1-11.

53. Tohma H, Gülçin İ, Bursal E, Gören AC, Alwasel SH, Köksal E. Antioxidant activity and phenolic compounds of ginger (Zingiber officinale Rosc.) determined by HPLC-MS/MS. J Food Meas Charact 2017;11(2):556-66.

54. Rampogu S, Baek A, Gajula RG, Zeb A, Bavi RS, Kumar $\mathrm{R}$ et al. Ginger (Zingiber officinale) phytochemicalsgingerenone-A and shogaol inhibit SaHPPK: Molecular docking, molecular dynamics simulations and in vitro approaches. Ann Clin Microbiol Antimicrob 2018;17(1):1-15.

55. Mostafa NM. Antibacterial activity of ginger (Zingiber officinale) leaves essential oil nanoemulsion against the cariogenic Streptococcus mutans. J Appl Pharm Sci 2018;8(9):34-41.

56. Lucky E, Igbinosa OE, Jonahan I. Antimicrobial Activity of Zingiber officinale Against Multidrug Resistant Microbial Isolates. Heal Sci Res 2017;4(6):76-81.

57. Awan UA, Ali S, Shahnawaz AM, Shafique I, Zafar A, Khan MAR et al. Biological activities of Allium sativum and Zingiber officinale extracts on clinically important bacterial pathogens, their phytochemical and FT-IR spectroscopic analysis. Pak J Pharm Sci 2017;30(3):72945.

58. Shareef HK, Muhammed HJ, Hussein HM, Hameed IH. Antibacterial effect of ginger (zingiber officinale) roscoe and bioactive chemical analysis using gas chromatography mass spectrum. Orient J Chem 2016;32(2):817-37.

59. Mathew S, Prakash A, Radhakrishnan EK. Sunlight mediated rapid synthesis of small size range silver nanoparticles using Zingiber officinale rhizome extract and its antibacterial activity analysis. Inorg Nano-Metal Chem 2018;48(2):139-45.

60. Yang N, Li F, Jian T, Liu C, Sun H, Wang L et al. Biogenic synthesis of silver nanoparticles using ginger (Zingiber officinale) extract and their antibacterial properties against aquatic pathogens. Acta Oceanol Sin 2017;36(12):95-100.

61. Nikolic M, Vasic S, Djurdjevic J, Stefanovic O, Comic L. Antibacterial and anti-biofilm activity of ginger (Zingiber officinale (Roscoe)) ethanolic extract. Kragujev J Sci 2014;36(36):129-36.

62. Mahady GB, Pendland SL, Yun GS, Lu Z-Z, Stoia A. Ginger (Zingiber officinale Roscoe) and the Gingerols Inhibit the Growth of Cag A+ Strains of Helicobacter pylori. Anticancer Res 2003;23(0):3699-3702.

63. Azizi A, Aghayan S, Zaker S, Shakeri M, Entezari N, Lawaf S. In vitro Effect of Zingiber officinale Extract on Growth of Streptococcus mutans and Streptococcus sanguinis. Int J Dent 2015.

64. Zainal-Abidin Z, Abdul-Wahab NA, Ghazi-Ahmad MK, Mohd-Said S. In vitro Antibacterial Activity of Zingiber officinale and Orthosiphon stamineus on Enterococcus faecalis. J Agric Sci 2017;9(13):112.

65. Hassan Balla Mohamed A. Antibacterial and Wound Healing Potential of Ethanolic Extract of \& lt; I \& gt; Zingiber Officinale \&lt;/i\&gt; in Albino Rats. J Dis Med Plants 2017;3(1):1.

66. Yusuf AA, Lawal B, Abubakar AN, Berinyuy EB, Omonije YO, Umar SI et al. In vitro antioxidants, antimicrobial and toxicological evaluation of Nigerian Zingiber officinale. Clin Phytoscience 2018; 4(1):2-9.

67. Chakotiya AS, Tanwar A, Narula A, Sharma RK. Zingiber officinale: Its antibacterial activity on Pseudomonas aeruginosa and mode of action evaluated by flow cytometry. Microb Pathog 2017;107:254-60.

68. Ashgar SS. Antibacterial activity of crude herbal extracts of Zingiber officinale and Curcuma longa against 13 reference bacterial species. Glob Adv Res J Med Med Sci [Internet] 2017;6(10):240-4. Available from: http://garj.org/garjmms

69. Nas F, Ali M, Ahmad A. In vitro Antibacterial Activity of Different Extracts of Zingiber Officinale against Bacterial Isolates Responsible for Food Spoilage. SOA Arch Pharm Pharmacol 2018;1(1):1.

70. Sabu R, Soumya KR, Radhakrishnan EK. Endophytic Nocardiopsis sp. from Zingiber officinale with both antiphytopathogenic mechanisms and antibiofilm activity against clinical isolates. 3 Biotech 2017;7(2). 